\title{
LA-UR-15-26640
}

Approved for public release; distribution is unlimited.

Title: Integrated Forest Management Charter

Author(s): Hansen, Leslie A.

Intended for: Charter Document

Environmental Programs

Issued: 
Disclaimer:

Los Alamos National Laboratory, an affirmative action/equal opportunity employer,is operated by the Los Alamos National Security, LLC for the National NuclearSecurity Administration of the U.S. Department of Energy under contract DE-AC52-06NA25396. By approving this article, the publisher recognizes that the U.S. Government retains nonexclusive, royalty-free license to publish or reproduce the published form of this contribution, or to allow others to do so, for U.S. Government purposes. Los Alamos National Laboratory requests that the publisher identify this article as work performed under the auspices of the U.S. Departmentof Energy. Los Alamos National Laboratory strongly supports academic freedom and a researcher's right to publish; as an institution, however, the Laboratory does not endorse the viewpoint of a publication or guarantee its technical correctness. 


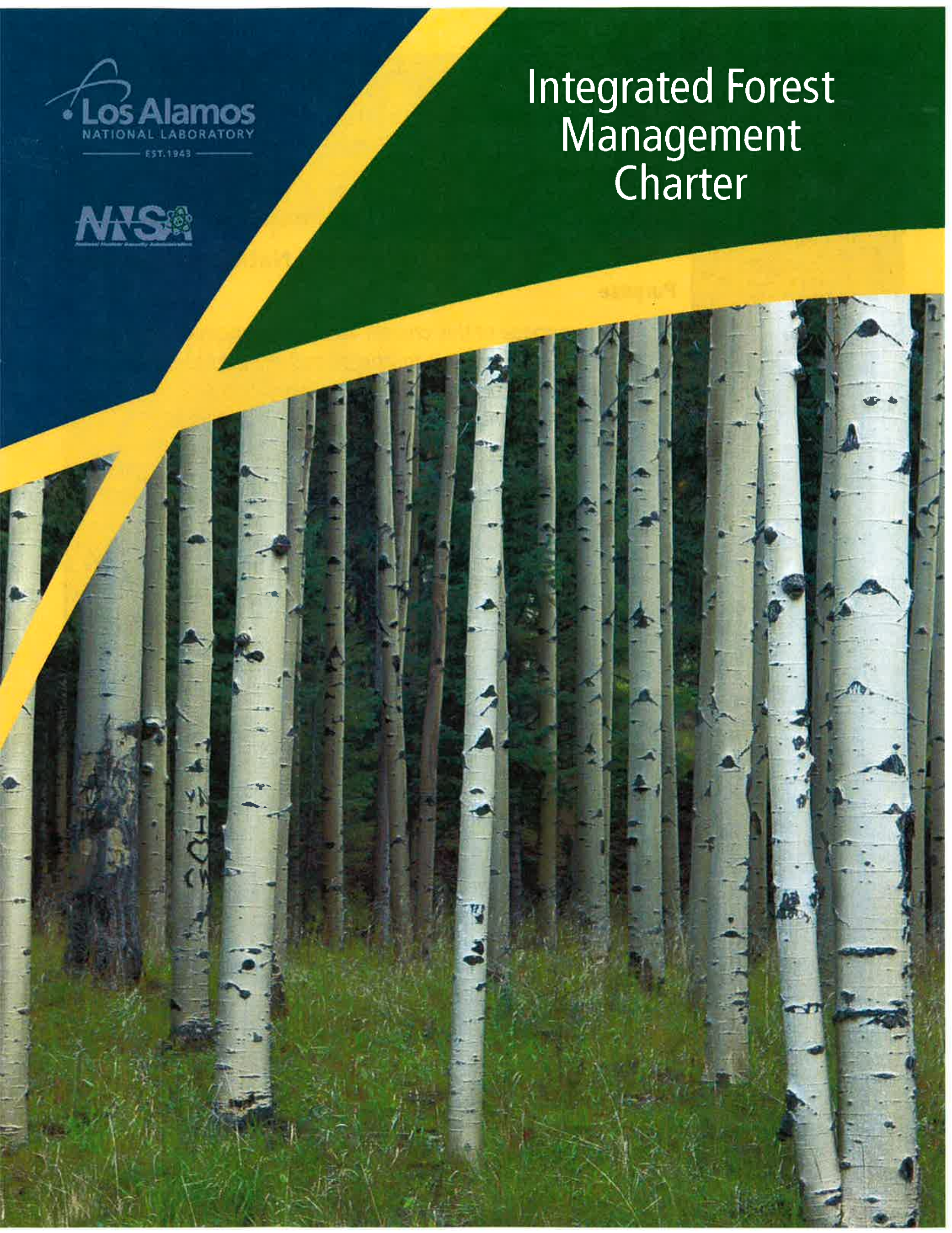




\section{Integrated Forest Management Charter}

\section{Los Alamos National Laboratory}

\section{Purpose}

The purpose of this charter is to establish, maintain, and implement programs for the protection, preservation, and enhancement of the land and water resources of Los Alamos National Laboratory in a changing climate.

- Ensure adequate resources are available to support the Forest Management and Wildland Fire program effort.

- Communicate and implement the Laboratory's Environmental Governing Policy and Institutional Objectives;

Emergency Management Governing Policy; and Wildland Fire Program.

- Provide transparency and enhanced communication to surrounding neighbors; regulators; and the public through community outreach.

\section{Background}

The majority of the Los Alamos National Laboratory (LANL) site consists of undeveloped lands. Currently, piñonjuniper woodlands are common at lower elevations while ponderosa pine with a minor Douglas fir - mixed conifer component is dominant at the higher elevations. Forests and woodlands provide habitat for wildlife and recreational and aesthetic value to humans. They stabilize soils and clean the air and water. And now, because of past management, wildfire, and climate change, forests and woodlands are facing unprecedented threats.

Wildfire is a recurring threat to LANL personnel, property and mission. The frequency, severity and extent of wildfires have been increasing throughout the western United States. Two major wildfires have impacted LANL facilities since 2000. In addition, current climate modeling indicates that northern New Mexico is on a trajectory of increasing temperature which

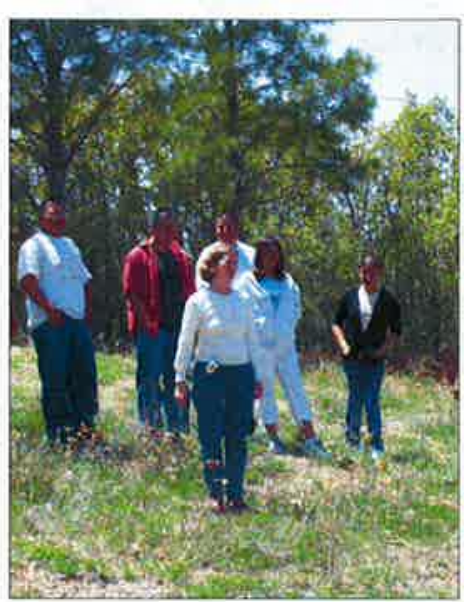

Alison Dorries, Division Leader for Environmental Protection provides forest tour for native American students.

will lead to high tree mortality due to drought stress, pathogens and wildfire. Current research predicts that native conifer forests and woodlands at Los Alamos will disappear or be heavily altered by 2050 


\section{Membership}

This working group is formed by a cooperative effort between the Associate Directorate for Security, Safeguards and Emergency Response (ADSSER) and the Associate Directorate for Environment, Safety, and Health (ADESH), with support by staff from other organizations.
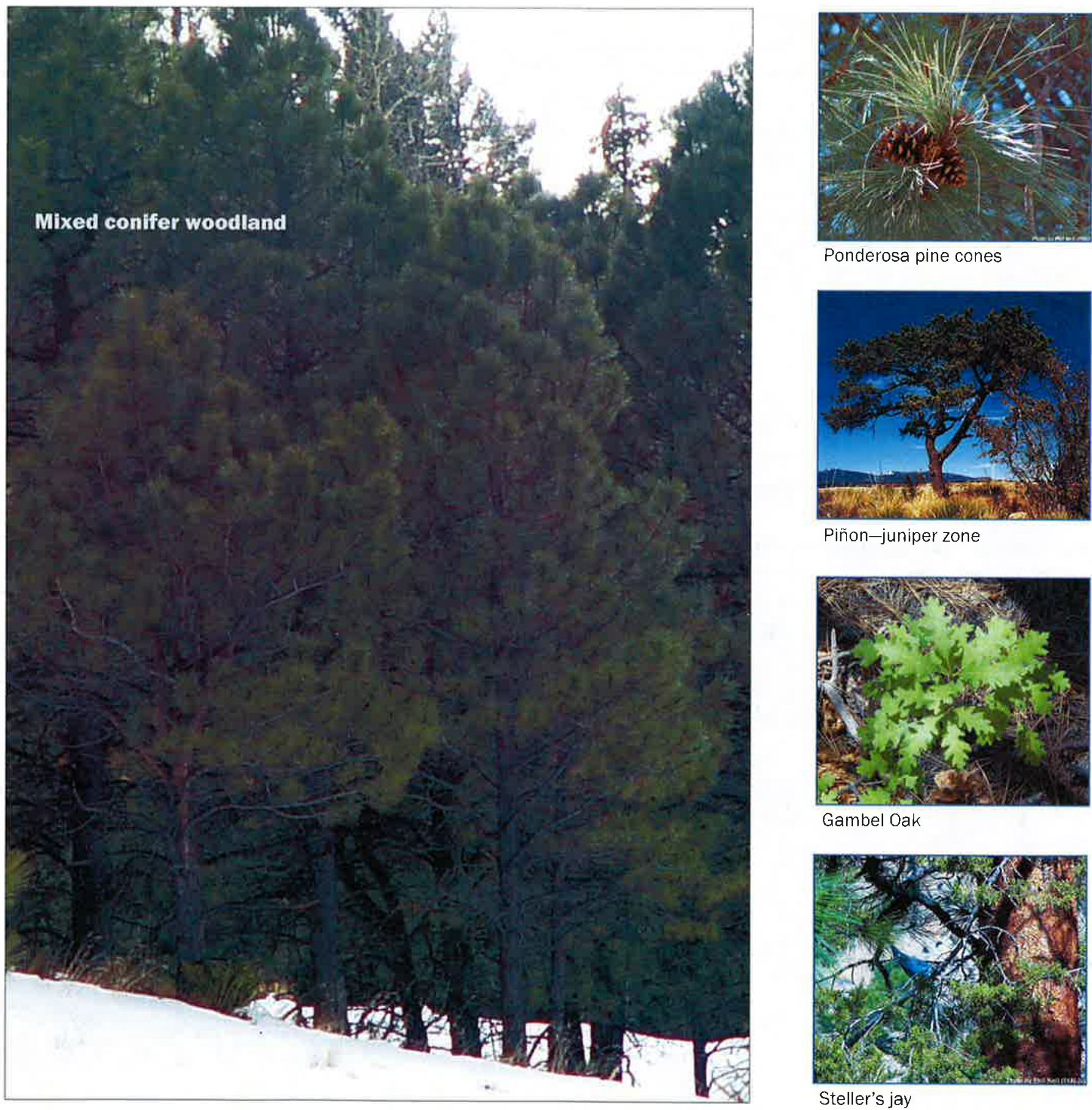

Ponderosa pine cones

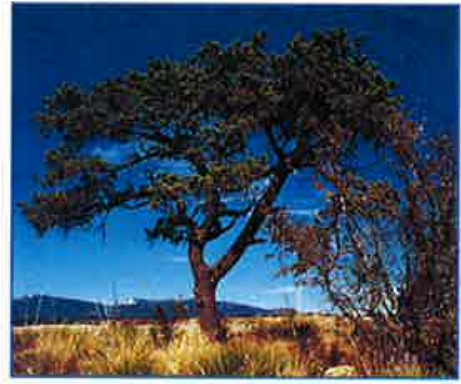

Piñon-juniper zone

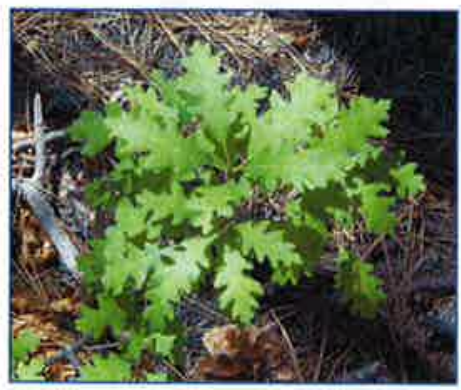

Gambel Oak

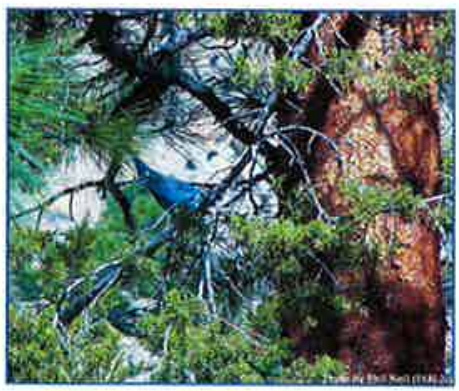

Steller's jay

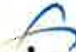




\section{Integrated Forest Management Charter}

\section{Goals}

- Manage LANL forests to support mission requirements, and security and operational needs while preserving forest habitat whenever feasible.

- Manage LANL forests in coordination with other LANL resource management plans, the Long-Term Strategy, and the Site-Wide EIS to achieve integrated and sustainable results.

- Prepare for ongoing climate change impacts to LANL forests by employing adaptive management strategies.

- Integrate management of LANL forest health with the resource management plans of adjoining federal, local and tribal jurisdictions to accomplish desired habitat and ecosystem objectives across jurisdictional boundaries.

- Preserve and protect existing LANL forests and promote regrowth and forest health at LANL.

- Use forest management to protect and improve surface water quality

\section{Objectives}

- Prepare for wildfires at LANL, including considering all appropriate science-based forest management options.

- Update and maintain NEPA coverage for all planned forest management activities.

- Fund pilot forest management projects in conjunction with other agencies and NGO's, and as part of the purpose of the LANL National Environmental Research Park.

- Employ LANL programmatic capabilities to improve LANL forest management, predictions and long-term scenarios.

- Require wildfire-aware site design for all LANL projects and construction to mitigate risk to life and property and enhance facility safety.

- Include forest health considerations as part of all LANL project reviews through the PR-ID and EX-ID process.
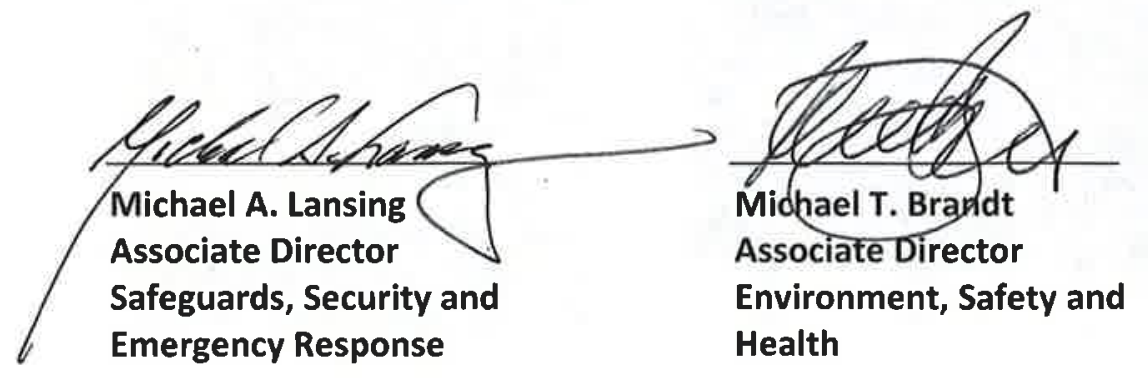

\section{Los Alamos National Laboratory}

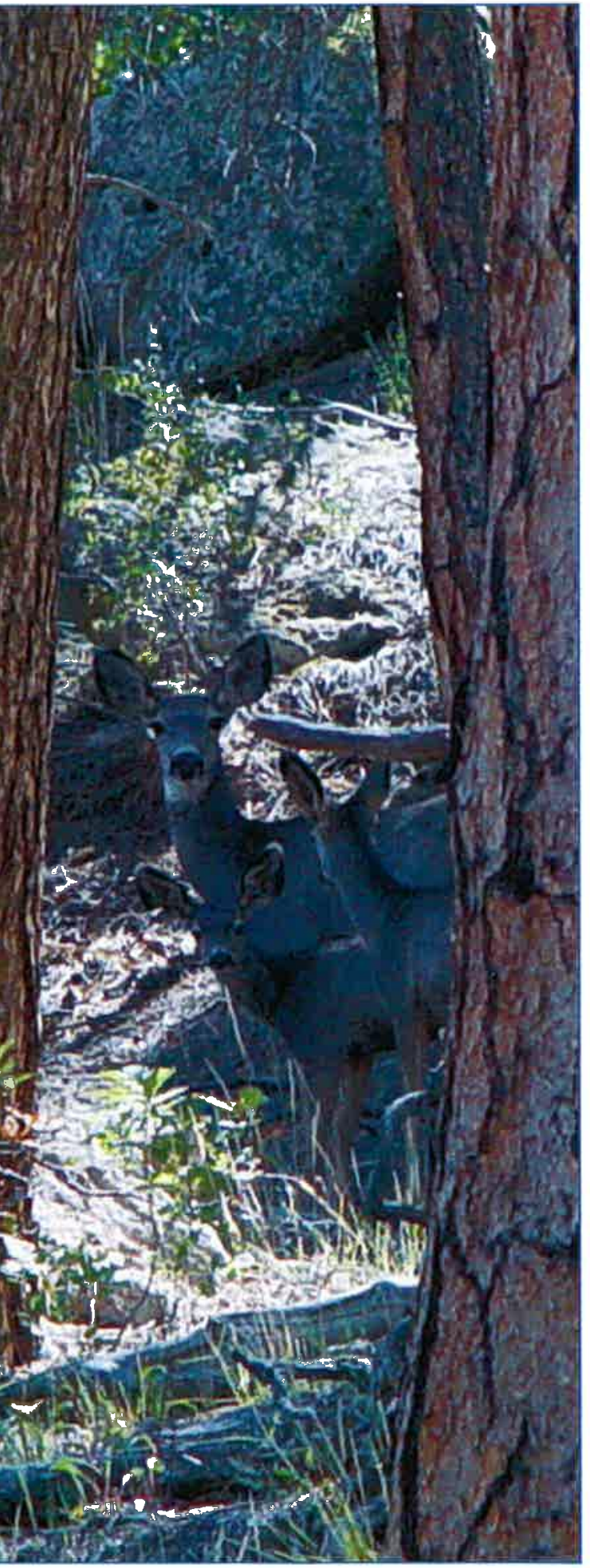

Mule deer peering between Ponderosa truncks 